\title{
Avoiding or Promoting Graphite in Carbon-Rich Chromium-Containing CoNiFer Cast Alloys-Part 2: Microstructures of the Elaborated Alloys
}

\author{
Ophélie Hestin, ${ }^{1}$ Elise Souaillat, ${ }^{1}$ Ahmed Dia, ${ }^{1}$ Moussa Ba, ${ }^{1}$ and Patrice Berthod ${ }^{1,2}$ \\ ${ }^{1}$ Faculty of Sciences and Technologies, University of Lorraine, Boulevard des Aiguillettes, B.P. 70239, \\ 54506 Vandoeuvre-lès-Nancy, France \\ ${ }^{2}$ Institut Jean Lamour (UMR CNRS 7198), Department of Chemistry and Physics of Solids and Surface, \\ Team 206 "Surface and Interface, Chemical Reactivity of Materials", Boulevard des Aiguillettes, B.P. 70239, \\ 54506 Vandoeuvre-lès-Nancy, France \\ Correspondence should be addressed to Patrice Berthod, patrice.berthod@ijl.nancy-universite.fr
}

Received 14 February 2012; Accepted 19 March 2012

Academic Editors: N. Choudhury and H. Hirao

Copyright () 2012 Ophélie Hestin et al. This is an open access article distributed under the Creative Commons Attribution License, which permits unrestricted use, distribution, and reproduction in any medium, provided the original work is properly cited.

Nine $\mathrm{M}-x \mathrm{Cr}-y \mathrm{C}$ ternary alloys, three cobalt based, three nickel based and three iron based, were elaborated by foundry, from chemical compositions previously selected by the mean of thermodynamic calculations. They were metallographically characterized, using electron microscopy, image analysis, and X-ray diffraction. The as-cast microstructures are in rather good agreement with the ones predicted at 500 and/or $600^{\circ} \mathrm{C}$, despite that the elaboration conditions did not meet any thermodynamic equilibrium criteria. Indeed, the obtained carbides and graphite fractions were close to the calculated ones, and the new chromium contents previously chosen effectively led to the expected microstructure modifications, notably almost total suppression of graphite in the nickel alloys and obtaining large fractions of carbides in the cobalt alloys. This allowed specifying the hardness evolution resulting, for these alloys, from the presence or absence of the soft graphite phase, and from the lowering or the enhancement of the carbides presence.

\section{Introduction}

The cast cobalt-based, nickel-based, and iron-based alloys are of great importance in many various fields. For example, the first ones are used since many years for artificial bone prostheses [1], for the frameworks reinforcing fixed partial dentures [2], or for aeronautical and power generation turbine disks [3]. The second ones can be also met in medical applications [4] notably when alloyed with titanium, turbine blades [5] notably when alloyed with aluminium, and centrifugal glass spinning tools [6] notably when alloyed with chromium. The applications of the third ones are too numerous to be cited. Among the common applications for which the three families are also taken in consideration, there are also cutting tools and hardfacing coatings for which carbon is added in high quantities in \{carbides-forming elements\}containing Co-based, Ni-based, and Fe-based alloys [7-9].
For such applications obtaining high carbide fractions is of great importance to ensure the previous properties and judicious choices must be done for the compositions of the alloys in order to obtain high carbide fractions by avoiding the appearance of phases detrimental for hardness as graphite, or inversely by promoting graphite for the improvement of the alloy's heat diffusivity. To help these choices, thermodynamic calculations can be carried out preliminarily. This was done in the first part of this work [10] in the case of ternary $\mathrm{Co}-\mathrm{Cr}-\mathrm{C}$, Ni-Cr-C, and Fe-Cr-C alloys, bases of chromium carbides-rich industrial alloys, with as a result the identification of several compositions possibly leading to the desired microstructures. In this second part, the chosen alloys were elaborated and metallographically characterized, to compare the obtained microstructures to the calculated ones, and also to specify their hardness values. 


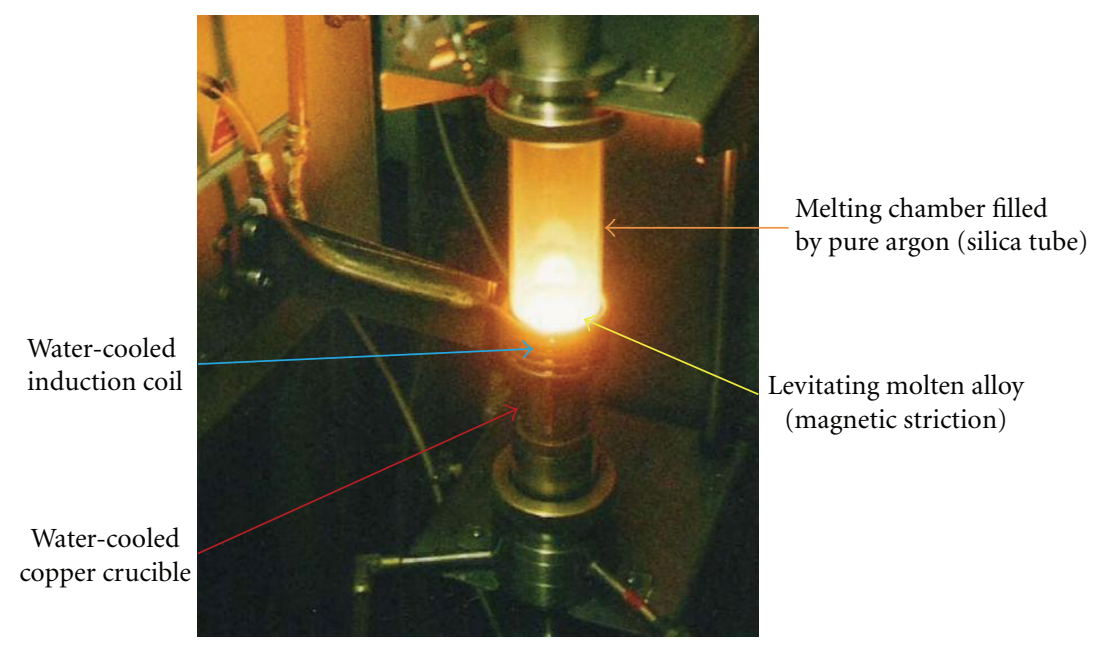

FIGURE 1: Elaboration of alloys by melting using a CELES high-frequency induction furnace.

\section{Experimental Methodology}

2.1. Elaboration of the Alloys. The compositions of the ternary alloys which were defined in the first part of this work are reminded bellow:

(i) cobalt alloys: Co-12Cr-3C (named "Co30/12Cr"), Co-15.5Cr-4C (named "Co40/16Cr") and Co-23Cr5C (named "Co50/23Cr”),

(ii) nickel alloys: Ni-25.5Cr-3C (named "Ni30/26Cr"), $\mathrm{Ni}-34.5 \mathrm{Cr}-4.5 \mathrm{C}$ (named "Ni45/35Cr") and Ni-37Cr5C (named "Ni50/37Cr"),

(iii) iron alloys: Fe-19.7Cr-3C (named "Fe30/20Cr"), Fe26.1Cr-4C (named "Fe40/26Cr") and Fe-32.6Cr-5C (named "Fe50/33Cr").

They were synthesized by foundry. Cobalt, nickel, or iron pure elements, mixed with pure chromium and graphite (>99.99 wt.\%), were melted by induction (frequency: about $100 \mathrm{kHz}$ ) in a copper crucible cooled by water circulation (Figure 1). All the high-temperature operations (heating, melting, solidification, solid-state cooling) were achieved in inert atmosphere to avoid oxidation and loss of any element (300 millibars of pure argon).

2.2. Metallography Preparation and Examinations. The ingots which were obtained (mass of $30 \mathrm{~g}$ typically) were cut using either a Delta Abrasimet cutter (Buehler) or an Isomet 5000 precision saw (Buehler), is depending on the machining difficulties. They were thereafter embedded in a Araldite resin DBF + hardener HY956 \} cold mixture (Escil), grinded using SiC papers with grades from 120 to 1200. After ultrasonic cleaning the mounted samples were polished with textile enriched with $1 \mu \mathrm{m}$-hard particles to obtain a mirrorlike state allowing the best conditions of metallographic observations.

The microstructures were qualitatively observed using a Philips XL30 Scanning Electron Microscope (SEM), in backscattered electron (BSE) mode, with an acceleration voltage of $20 \mathrm{kV}$. Electronic micrographs were taken, for a double use: microstructure illustration and measurements of the surface fractions of the different phases present by image analysis (Adobe Photoshop). X-Ray diffraction (XRD) runs were performed with a Philips X'Pert Pro diffractometer (wavelength $\mathrm{Cu} \mathrm{K} \alpha$ : 1.5406 Angströms) to better know the carbides stoichiometry. The phases present in the alloys were also quantitatively analyzed since the surface fractions of carbides and graphite were measured on three $\times 1000$ SEM/BSE pictures to assess an average value and a standard deviation value for each alloy, using the Adobe Photoshop CS software.

2.3. Hardness Measurements. To finish, all the alloys were subjected to Vickers indentation with a load of $30 \mathrm{~kg}$, using a Testwell Wolpert apparatus. Three indentations were performed to obtain average and standard deviation values.

\section{Results and Discussion}

3.1. As-Cast Microstructures. The microstructures of the obtained alloys in their as-cast conditions are illustrated by the micrographs presented in Figure 2 for the cobalt alloys, Figure 3 for the nickel alloys, and Figure 4 for the iron alloys. In each case, the microstructures of the initial alloys (i.e., the ones which contain $30 \mathrm{wt} . \% \mathrm{Cr}$ ) are reminded using a small micrograph placed in the top-left corner of the micrographs of the Cr-modified alloys.

Concerning the cobalt-based alloys (Figure 2), it appears that the decrease in chromium content involved the appearance of significant quantities of graphite in the alloy containing $3 \mathrm{wt} . \%$ of carbon. This graphite is clearly lamellar, as it was in the carbon-richest nickel alloy previously studied. If the Co30/12Cr alloy has remained hypoeutectic, the decrease down to $16 \mathrm{wt} . \%$ of the $4 \mathrm{wt}$.\% C-containing alloy- not only promoted the development of many graphite flakes toobut also changed the position of the microstructure type by regard to eutectic: if the initial Co40 alloy was hypereutectic (presence of coarse proeutectic carbides), the Crimpoverished Co40 is now hypoeutectic, as demonstrated by 


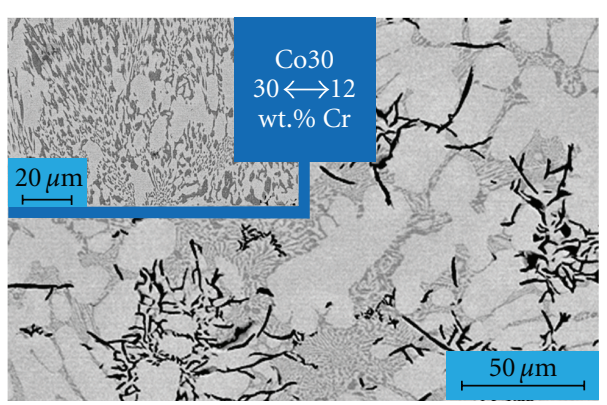

(a)

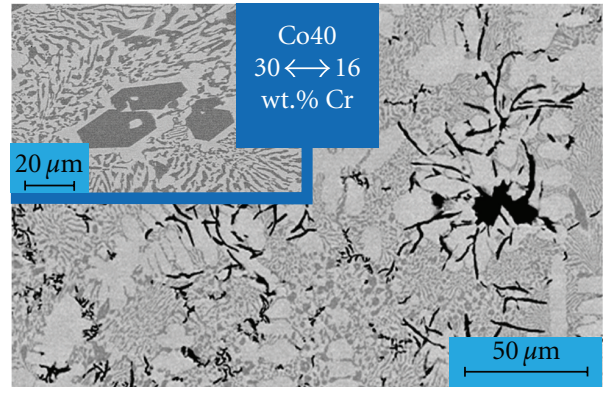

(b)

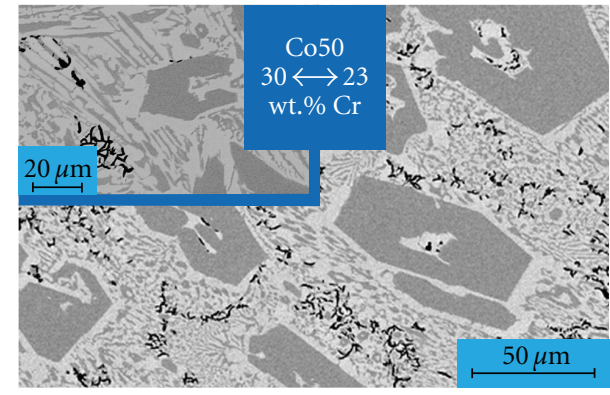

(c)

Figure 2: Microstructures of the Co-12Cr-3C, Co-15.5Cr-4C and Co-23Cr-5C alloys, to compare with the previous $\{30 \mathrm{wt} . \% \mathrm{Cr}\}-$ containing alloys (top-left inlaid micrographs).

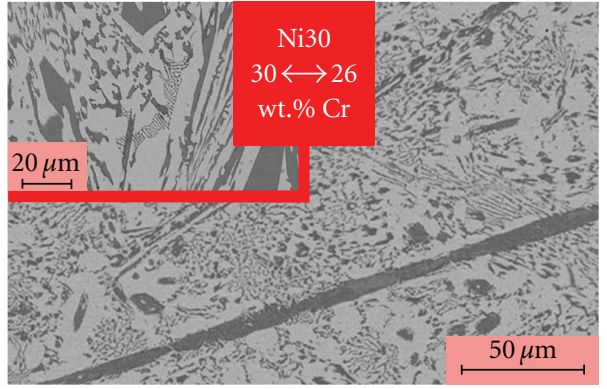

(a)

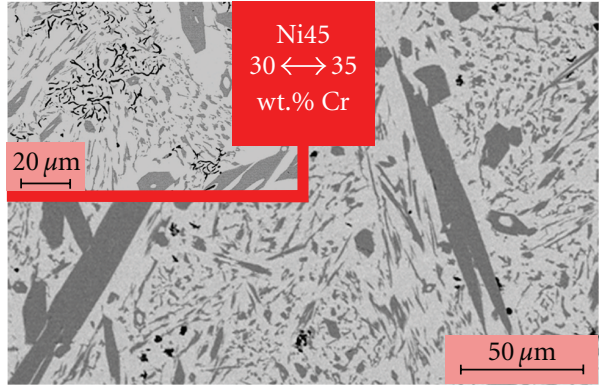

(b)

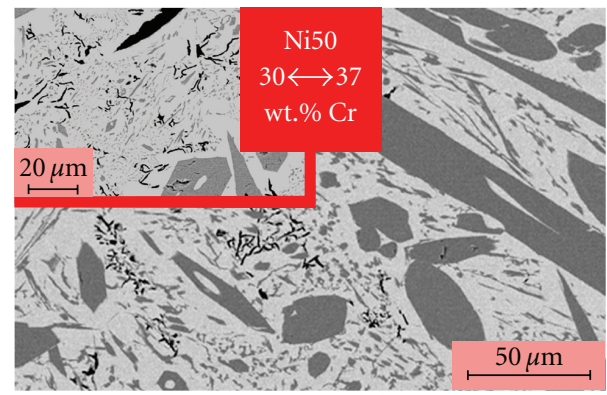

(c)

Figure 3: Microstructures of the Ni-25.5Cr-3C, Ni-34.5Cr-4.5C, and Ni-37Cr-5C alloys, to compare with the previous $\{30 \mathrm{wt} . \% \mathrm{Cr}\}-$ containing alloys (top-left inlaid micrographs).

the presence of dendrites of matrix. In contrast, the decrease down to 23 wt.\% Cr in the Co50 alloy did not modify the character of its microstructure (still hyper-eutectic) but only favored the presence of more graphite than in the initial alloy.
In contrast, for the nickel-based alloys, the impoverishment in chromium of the Ni30 alloy and the enrichment of the Ni45 and Ni50 alloys in the same element did not modify the position of the alloys by regard to the eutectic. They are all 


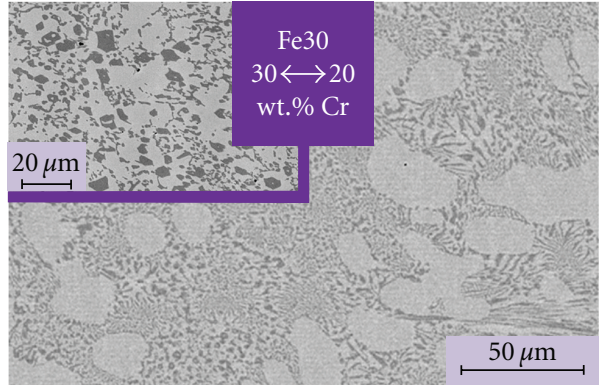

(a)

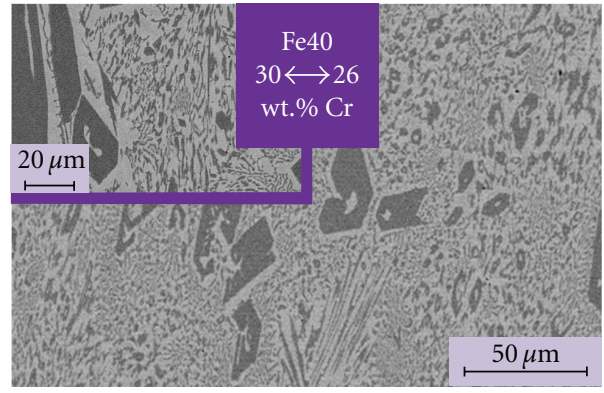

(b)

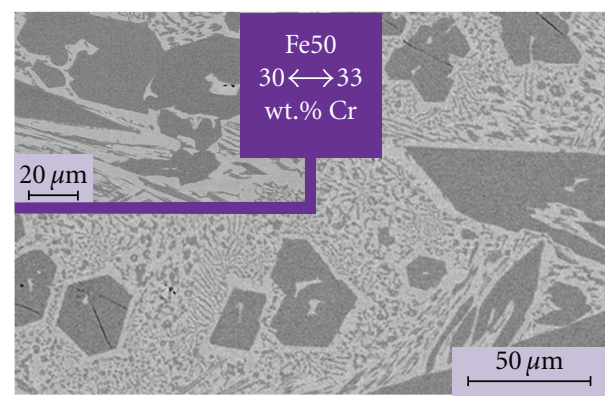

(c)

Figure 4: Microstructures of the Fe-19.7Cr-3C, Fe-26.1Cr-4C, and Fe-32.6Cr-5C alloys, to compare with the previous $\{30$ wt.\% Cr $\}-$ containing alloys (top-left inlaid micrographs).

TABLE 1: Measured surface fractions of carbides and graphite and comparison with the volume fractions issued from the mass fractions calculated at $500^{\circ} \mathrm{C}[10]$ : case of the Co-based alloys.

\begin{tabular}{lccccccccc}
\hline calc. vol.\% and measured surf. \% & \multicolumn{3}{c}{ Co- $x$ Cr-3C } & \multicolumn{2}{c}{ Co- $y$ Cr-4C } & \multicolumn{2}{c}{ Co- $z$ Cr-5C } \\
\hline wt.\% Cr & 30 & 12 & 12 (meas.) & 30 & 15.5 & 15.5 (meas.) & 30 & 23 & 23 (meas.) \\
Carbides & 38.1 & 15.2 & $16.6 \pm 1.1$ & 40.4 & 19.4 & $24.2 \pm 0.8$ & 37.7 & 28.5 & $44.1 \pm 6.3$ \\
Graphite & 0 & 3.87 & $4.87 \pm 0.26$ & 0 & 5.32 & $5.82 \pm 0.37$ & 1.26 & 4.78 & $3.05 \pm 0.56$ \\
\hline
\end{tabular}

hypereutectic. The decrease in chromium content of the Ni30 alloy did not induce the appearance of graphite, as expected. In contrast, the chromium enrichment of the graphitecontaining Ni45 and Ni50 alloys was obviously not high enough to really suppress graphite in their microstructures, although that the volume fraction was significantly decreased by this change of $\mathrm{Cr}$ content.

Concerning the iron-based alloys, the Cr-impoverishment of the Fe30 and the Fe40 alloys did not promote the appearance of graphite, but it changed the position of the first one by regard to the eutectic since the Fe30 nature changed from hypereutectic to hypoeutectic. However, the slight increase in chromium content for the Fe50 alloy did not involve any significant rise of the carbide surface fraction.

3.2. Results of Image Analysis and Comparison with Thermodynamic Calculations. The estimation of the carbides fractions (without distinction between the possible different carbides present) and of the graphite fractions was done by surface fraction measurement by image analysis. The results are given in Table 1 for the Co-based alloys, Table 2 for the Ni-based alloys, and Tables 3 and 4 for the Fe-based alloys.
One can remind that predictions concerning the quantities of the present phases were obtained for $500^{\circ} \mathrm{C}$ for the three alloy families (and also $600^{\circ} \mathrm{C}$ for the iron alloys) in terms of mass fractions [10], using the Thermo-Calc software and an appropriate database [11-23]. These results were converted into volume fractions using the following values of density:

(i) 7.95 (Co alloys), 8.12 (Ni alloys) and $7.29 \mathrm{~g} \mathrm{~cm}^{-3}$ for the matrix (deduced from the volume and masses of binary samples),

(ii) $6.86 \mathrm{~g} \mathrm{~cm}^{-3}$ for the carbides whatever their nature (average value of 6.97 for $\mathrm{Cr}_{23} \mathrm{C}_{6}, 6.92$ for $\mathrm{Cr}_{7} \mathrm{C}_{3}$, and 6.68 for $\left.\mathrm{Cr}_{3} \mathrm{C}_{2}[24]\right)$,

(iii) $2.25 \mathrm{~g} \mathrm{~cm}^{-3}$ for graphite.

The results are added to the tables to facilitate comparisons between measurements and calculations. Since two temperatures were considered for the iron alloys, for which they were theoretically a significant discontinuity between 600 and $500^{\circ} \mathrm{C}$ in term of carbide fractions (because the change of $\mathrm{M}_{7} \mathrm{C}_{3}$ into $\mathrm{M}_{3} \mathrm{C}_{2}$ ), the results are given in two distinct tables for these alloys, Table 3 with the theoretic 
TABLE 2: Measured surface fractions of carbides and graphite and comparison with the volume fractions issued from the mass fractions calculated at $500^{\circ} \mathrm{C}[10]$ : case of the Ni-based alloys.

\begin{tabular}{lccccccccc}
\hline calc. vol.\% and measured surf. \% & \multicolumn{3}{c}{ Ni- $x$ Cr-3C } & \multicolumn{2}{c}{ Ni- $y$ Cr-4.5C } & Ni- $z$ Cr-5C \\
\hline wt.\% Cr & 30 & 25.5 & 25.5 (meas.) & 30 & 34.5 & 34.5 (meas.) & 30 & 37 & 37 (meas.) \\
Carbides & 29.4 & 25.5 & $30.2 \pm 2.2$ & 33.8 & 37.5 & $28.8 \pm 1.3$ & 33.4 & 41.4 & $32.0 \pm 4.4$ \\
Graphite & 0 & 0 & 0 & 1.42 & 0 & $0.23 \pm 0.09$ & 3.04 & 0 & $0.63 \pm 0.09$ \\
\hline
\end{tabular}

TABLE 3: Measured surface fractions of carbides and graphite and comparison with the volume fractions issued from the mass fractions calculated at $500^{\circ} \mathrm{C}[10]$ : case of the Fe-based alloys.

\begin{tabular}{|c|c|c|c|c|c|c|c|c|c|}
\hline \multirow{2}{*}{$\begin{array}{l}\text { calc. vol. } \% \text { and measured surf. } \% \\
\text { wt. } \% \text { Cr }\end{array}$} & \multicolumn{3}{|c|}{$\mathrm{Fe}-x \mathrm{Cr}-3 \mathrm{C}$} & \multicolumn{3}{|c|}{ Fe- $y$ Cr- $4 \mathrm{C}$} & \multicolumn{3}{|c|}{$\mathrm{Fe}-z \mathrm{Cr}-5 \mathrm{C}$} \\
\hline & 30 & 19.7 & 19.7 (meas.) & 30 & 26.1 & 26.1 (meas.) & 30 & 32.6 & 32.6 (meas.) \\
\hline Carbides & 34.8 & 23.6 & $24.6 \pm 1.7$ & 46.7 & 31.3 & $36.2 \pm 3.2$ & 35.6 & 38.9 & $47.8 \pm 0.9$ \\
\hline Graphite & 0 & 0 & 0 & 0 & 0 & 0 & 1.26 & 0 & 0 \\
\hline
\end{tabular}

TABLE 4: Measured surface fractions of carbides and graphite and comparison with the volume fractions issued from the mass fractions calculated at $600^{\circ} \mathrm{C}[10]$ : case of the Fe-based alloys.

\begin{tabular}{|c|c|c|c|c|c|c|c|c|c|}
\hline \multirow{2}{*}{$\begin{array}{l}\text { calc. vol. } \% \text { and measured surf. \% } \\
\text { wt. } \% \text { Cr }\end{array}$} & \multicolumn{3}{|c|}{$\mathrm{Fe}-x \mathrm{Cr}-3 \mathrm{C}$} & \multicolumn{3}{|c|}{$\mathrm{Fe}-y \mathrm{Cr}-4 \mathrm{C}$} & \multicolumn{3}{|c|}{$\mathrm{Fe}-z \mathrm{Cr}-5 \mathrm{C}$} \\
\hline & 30 & 19.7 & 19.7 (meas.) & 30 & 26.1 & 26.1 (meas.) & 30 & 32.6 & 32.6 (meas.) \\
\hline Carbides & 34.9 & 35.5 & $24.6 \pm 1.7$ & 46.7 & 47.0 & $36.2 \pm 3.2$ & 58.5 & 58.3 & $47.8 \pm 0.9$ \\
\hline Graphite & 0 & 0 & 0 & 0 & 0 & 0 & 0 & 0 & 0 \\
\hline
\end{tabular}

results calculated for $500^{\circ} \mathrm{C}$, and Table 4 with the theoretic results calculated for $600^{\circ} \mathrm{C}$.

Concerning the Co alloys, one finds logically again, with the volume fractions deduced from the calculated mass fractions, that graphite should exist in significant quantities, thanks to their low density, and also that the proportion of carbides should be decreased (volume fraction divided by 2 for the Co40, and even by a higher factor for the Co30 one). The experimental results are rather in good agreement with the ones issued from calculations at $500^{\circ} \mathrm{C}$, especially in the case of the Co30/12Cr alloy concerning the carbides.

The carbide fraction lowering for the Ni30/26Cr and increase for the two other $\mathrm{Cr}$-modified Ni alloys are also found again in the calculated results converted in volume fractions, as well as the graphite suppression in the two latter cases. On the contrary, the measured surface fraction of carbide for the as-cast Ni30/26Cr is higher than predicted at $500^{\circ} \mathrm{C}$, and lower than predicted for the two other alloys. For the latter ones, the mismatch seems resulting from another mismatch, concerning graphite. Indeed, as qualitatively noted above, graphite is not totally suppressed and small quantities remain in the as-cast microstructures of these alloys. These graphite particles involve a small part of carbon which is consequently not used as carbides.

Finally, concerning the Fe alloys, the correspondence between calculations and measurements is very good again about graphite. Indeed, no graphite was expected and no graphite was obtained. In contrast, except for the Fe30/20Cr for values calculated at $500^{\circ} \mathrm{C}$, there are significant mismatches between the calculated volume fractions and the measured surface fractions. The experimental surface fractions tend to be higher than the volume fractions calculated

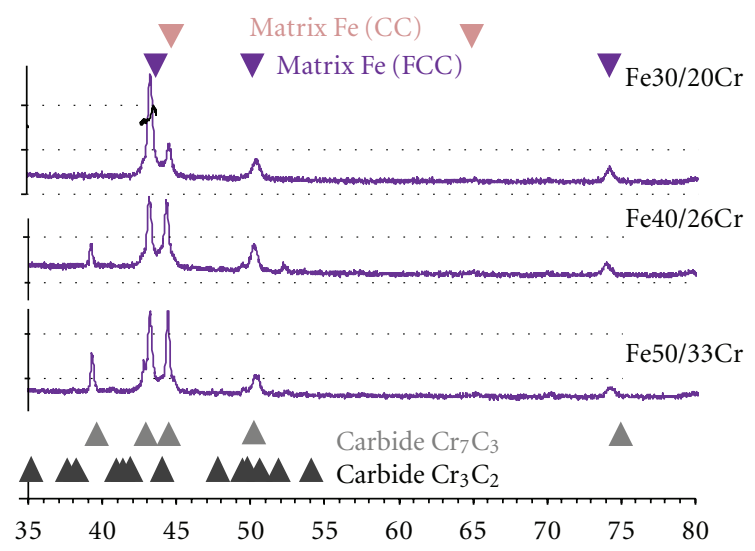

FIGURE 5: Spectra of X-Ray diffraction analysis obtained for the three Cr-modified iron alloys.

for a thermodynamic equilibrium at $500^{\circ} \mathrm{C}$, and lower than the same ones for calculations performed for $600^{\circ} \mathrm{C}$. The fact that the carbide surface fractions experimentally obtained are comprised between the carbides volume fractions calculated at $500^{\circ} \mathrm{C}$, and the one calculated at $500^{\circ} \mathrm{C}$ let think that the as-cast microstructures of these alloys are perhaps intermediate, with the $\mathrm{M}_{7} \mathrm{C}_{3}$ existing at $600^{\circ} \mathrm{C}$ which would be only partially transformed in $\mathrm{M}_{3} \mathrm{C}_{2}$ during the end of the cooling. The XRD results, presented in Figure 5, confirm this hypothesis since diffraction peaks of $\mathrm{M}_{3} \mathrm{C}_{2}$ co-exist with the $\mathrm{M}_{7} \mathrm{C}_{3}$ ones. One can also notice that the matrix has partially kept its high temperature crystal network (FCC) since there is coexistence of diffraction peaks of the austenitic form and of the ferritic form of the matrix. 
TABle 5: Average and standard deviation values of the hardness of the as-cast studied alloys, with comparison to the initial $30 \mathrm{wt} . \%$ Cr-containing alloys.

\begin{tabular}{|c|c|c|c|c|c|c|}
\hline Co alloys & Co30 & $\mathrm{Co} 30 / 12 \mathrm{Cr}$ & Co40 & $\mathrm{Co} 40 / 16 \mathrm{Cr}$ & Co50 & $\mathrm{Co} 50 / 23 \mathrm{Cr}$ \\
\hline Average & 619 & 308 & 633 & 340 & 642 & 496 \\
\hline Std Dev. & \pm 16 & \pm 8 & \pm 9 & \pm 17 & \pm 11 & \pm 10 \\
\hline Ni alloys & Ni30 & $\mathrm{Ni} 30 / 26 \mathrm{Cr}$ & $\mathrm{Ni45}$ & $\mathrm{Ni} 45 / 35 \mathrm{Cr}$ & Ni50 & $\mathrm{Ni50/37Cr}$ \\
\hline Average & 336 & 364 & 322 & 379 & 328 & 372 \\
\hline Std Dev. & \pm 21 & \pm 28 & \pm 5 & \pm 15 & \pm 9 & \pm 11 \\
\hline Fe alloys & Fe30 & $\mathrm{Fe} 30 / 20 \mathrm{Cr}$ & $\mathrm{Fe} 40$ & $\mathrm{Fe} 40 / 26 \mathrm{Cr}$ & Fe50 & $\mathrm{Fe} 50 / 33 \mathrm{Cr}$ \\
\hline Average & 605 & 535 & 629 & 674 & 753 & 741 \\
\hline Std Dev. & \pm 58 & \pm 14 & \pm 39 & \pm 31 & \pm 29 & \pm 34 \\
\hline
\end{tabular}

3.3. Hardness of the Alloys. In order to value the consequences of the variations in carbide fraction and of the presence/absence of graphite in the microstructures of the alloys on their hardness, Vickers indentations were performed under $30 \mathrm{~kg}$, load necessarily chosen rather high for such carbide-rich alloys. The results are given in Table 5, with the values earlier obtained for the Cr-unmodified alloys, for comparison.

One can see that the presence of graphite in the cobalt alloys, consequences of the decrease in chromium content, leads to a significant loss of hardness, while its suppression in the two carbon-richest nickel alloys, thanks to their increased chromium contents, promotes high values of hardness. These values are, however, lower than the ones of the cobalt alloys, the matrix of which is intrinsically harder than the nickelalloys one, except of course when graphite was favored by a lowered $\mathrm{Cr}$ content in the cobalt alloys. In contrast, the variations in chromium contents in the iron alloys do not induce so sensible hardness modifications, in alloys which are already very high, thanks to their initial very high carbide fractions.

It is logical that the very soft graphite phase and the very hard carbides (more than $1000 \mathrm{Hv}$ [25]) play an important role in the total hardness of the whole alloy, and such influence of the microstructure consequences of the chromium modifications were expected.

In contrast, the variations of the indentation results on a same alloy (some standard deviation values are high), induce a not so obvious hierarchy in some cases. One can suspect that the microstructure orientation of the hard interdendritic carbide-matrix eutectic in hypoeutectic alloys, and the orientation of the very hard coarse and elongated pro-eutectic carbides in hypereutectic alloys, may play too an additional important role.

\section{Conclusion}

The microstructures which were really obtained with the chemical compositions chosen with the help of the preliminary thermodynamic calculations were thus in conform with what was predicted, even if it was the as-cast (not thermodynamically equilibrated) microstructures which were characterized and compared to calculations. Due to this good agreement, the thermodynamic calculations which were carried out in the first part of this work, more precisely the ones performed at 500 and $600^{\circ} \mathrm{C}$ (temperatures at which one can think that further transformations are now really possible in conditions of fast temperature decrease), gave a good estimation of the nature and the proportions of the phases really obtained, despite the rather fast solidification and solid-state cooling, and, therefore, of the hardness potential of the alloys.

\section{Acknowledgment}

The authors are grateful to Lionel Aranda and Thierry Schweitzer for their technical help, to Sandrine Mathieu for the SEM examinations, and to Pascal Villeger for the XRD analyses.

\section{References}

[1] C. A. Homsy, R. F. Stanley, M. S. Anderson, and J. W. King, "Reduction of tissue and bone adhesion to cobalt alloy fixation appliances," Journal of Biomedical Materials Research, vol. 6, no. 5, pp. 451-464, 1972.

[2] R. E. Draddy, "Chrome-cobalt alloy pontics for fixed partial dentures," The Journal of Prosthetic Dentistry, vol. 25, no. 6, pp. 638-641, 1971.

[3] M. Marty and A. Walder, "Cobalt base alloys fabricated by powder metallurgy for compressor and turbine disks," in Proceedings of the 5th European Symposium on Powder Metallurgy, vol. 2, p. 200, 1978.

[4] M. Miyagi, "Medical application and biocompatibility of titanium-nickel (TiNi) alloy," Nippon Kinzoku Gakkai Kaiho, vol. 24, no. 1, p. 69, 1985.

[5] C. Just, "New nickel alloy for gas turbine blading," Sulzer Technical Review, vol. 62, no. 1, pp. 27-29, 1980.

[6] S. Vasseur, "Nickel alloy for centrifugal spinning apparatus for manufacture of glass fibers," European Patent Appllication no. EP 511099 A1, 1992.

[7] Y. Masumoto and S. Imasato, "Extremely hard sintered cobalt base alloy," Nippon Tungsten Review, vol. 18, p. 23, 1985.

[8] J. C. Miranda and A. Ramalho, "Abrasion resistance of thermal sprayed composite coatings with a nickel alloy matrix and a WC hard phase. Effect of deposition technique and remelting," Tribology Letters, vol. 11, no. 1, pp. 37-48, 2001.

[9] K. Ando, T. Kikko, and Y. Yoshida, "Toyota Jidosha Kabushiki Kaisha," International Application no. WO 2011101706 A1, 2011.

[10] P. Berthod, "Avoiding or promoting graphite in carbon-rich chromium-containing CoNiFer cast alloys. Part 1: Preliminary thermodynamic exploration," IRSN Thermodynamics, vol. 2012, Article ID 308795, 7 pages, 2012.

[11] Thermo-Calc Version N, Foundation for Computational Thermodynamics, Stockholm, Sweden, 2000.

[12] A. Fernandez Guillermet, "Critical evaluation of the thermodynamic properties of cobalt," International Journal of Thermophysics, vol. 8, pp. 481-510, 1987.

[13] J. O. Andersson, "Thermodynamic properties of chromium," International Journal of Thermophysics, vol. 6, pp. 411-419, 1985.

[14] P. Gustafson, "An evaluation of the thermodynamic properties and the P, T phase diagram of carbon," Carbon, vol. 24, no. 2, pp. 169-176, 1986. 
[15] A. F. Guillermet, "Thermodynamic analysis of The Co-C system," Zeitschrift fuer Metallkunde, vol. 78, no. 10, pp. 700-709, 1987.

[16] J. O. Andersson, “Thermodynamic properties of Cr-C," Calphad, vol. 11, no. 3, pp. 271-276, 1987.

[17] A. F. Guillermet, "Thermodynamic properties of the Fe-Co-C system," Zeitschrift fuer Metallkunde, vol. 79, no. 5, pp. 317329, 1988.

[18] A. Dinsdale and T. Chart, MTDS NPL, unpublished work, 1986.

[19] A. Gabriel, C. Chatillon, and I. Ansara, "Thermochemical and phase diagram analysis of the Ni-C, Co-C, and $\mathrm{Co}-\mathrm{Ni}-\mathrm{C}$ systems," High Temperature Science, vol. 25, no. 1, pp. 17-54, 1988.

[20] A. Fernandez Guillermet and P. Gustafson, "Assessment of the thermodynamic properties and the $(\mathrm{P}, \mathrm{T})$ phase diagram of iron," High Temperatures-High Pressures, vol. 16, no. 6, pp. 591-610, 1984.

[21] J. O. Andersson and B. Sundman, "Thermodynamic properties of the CrFe system," Calphad, vol. 11, no. 1, pp. 83-92, 1987.

[22] P. Gustafson, "Thermodynamic evaluation of the Fe-C system," Scandinavian Journal of Metallurgy, vol. 14, no. 5, pp. 259-267, 1985.

[23] J. O. Andersson, "A thermodynamic evaluation of the Fe-Cr-C system," Metallurgical Transactions A, vol. 19, no. 3, pp. 627636, 1988.

[24] P. T. B. Shaffer, High Temperature Materials. I: Materials Index, Plenum Press Handbooks, 1964.

[25] G.V. Samsonov, Handbooks of High-Temperature materials N 2 Properties Index, Plenum Press, New York, NY, USA, 1964. 

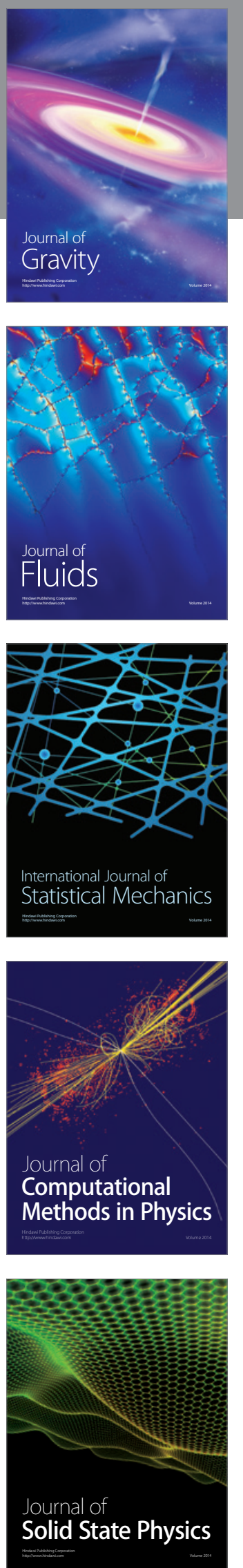
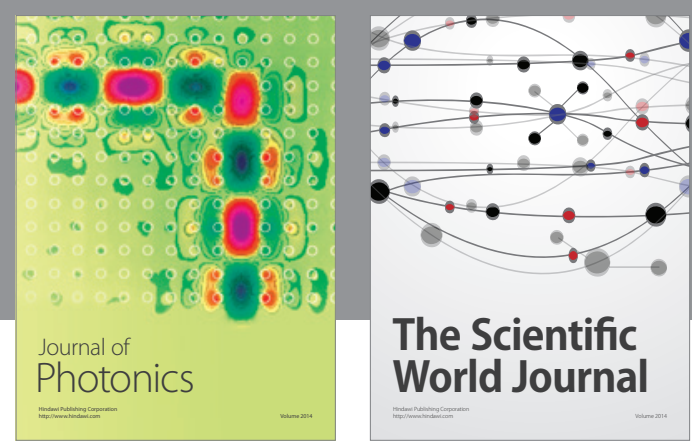

The Scientific World Journal

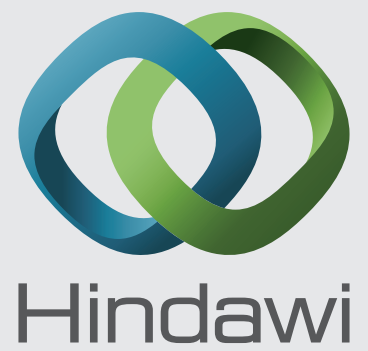

Submit your manuscripts at http://www.hindawi.com
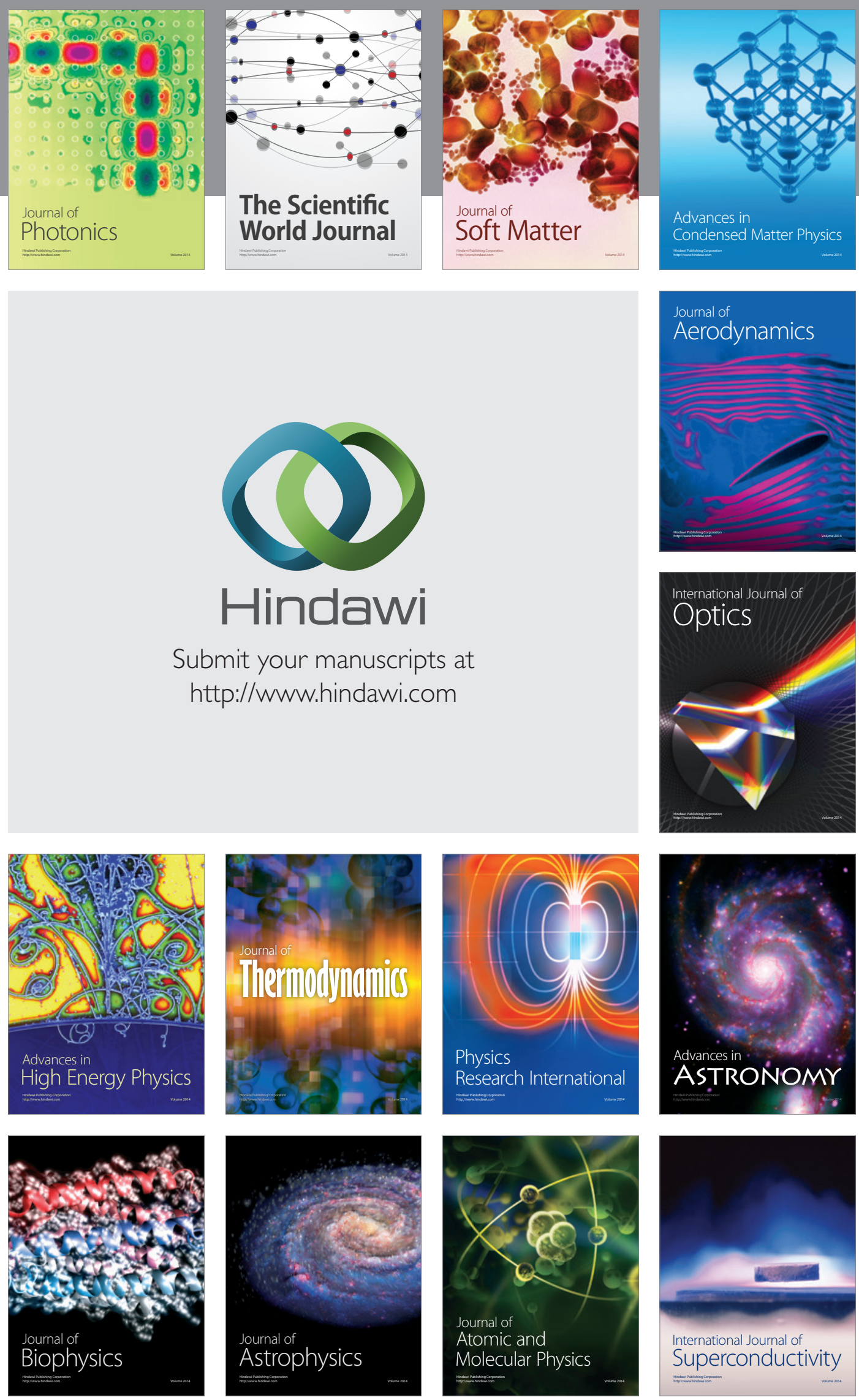
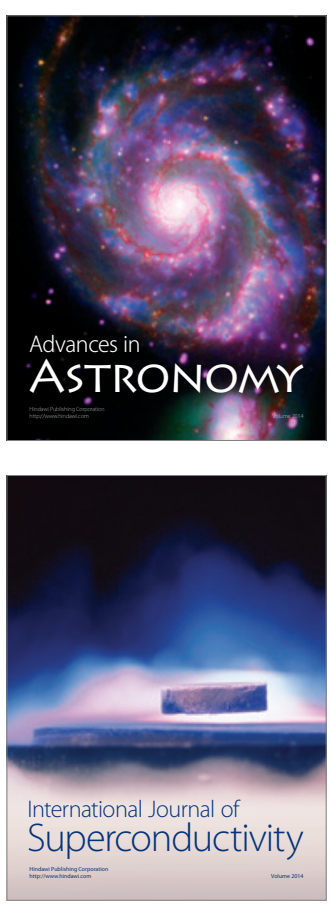